Research Paper

\title{
Analysis of the perceptions and attitudes to participate in radical and palliative clinical trials among Chinese lymphoma and head/neck cancer patients
}

\author{
Qiu-Huan Kong1,2*, Lu-Ping Yang1,2*, Yue-Rong Lai ${ }^{2,3}$, Hui-Ying Qin ${ }^{2,4}$, Lian-Zhu He2,5, Yu-Shan Liu ${ }^{1,2}$,

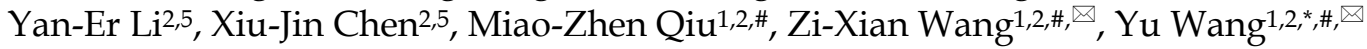 \\ 1. Department of Medical Oncology, Sun Yat-Sen University Cancer Center, Guangzhou 510060, China \\ 2. Sun Yat-sen University Cancer Center; State Key Laboratory of Oncology in South China; Collaborative Innovation Center for Cancer Medicine, Guangzhou \\ 510060, China \\ 3. Department of Gynecological Oncology, Sun Yat-Sen University Cancer Center, Guangzhou 510060, China \\ 4. Department of Nursing, Sun Yat-Sen University Cancer Center, Guangzhou 510060, China \\ 5. Department of Clinical Research, Sun Yat-Sen University Cancer Center, Guangzhou 510060, China \\ *Qiu-Huan Kong, Lu-Ping Yang, and Yu Wang contributed equally to this work.
}

\# Joint senior authors.

$\square$ Corresponding authors: Yu Wang, Department of Medical Oncology, Sun Yat-Sen University Cancer Center, 651 Dong Fend Road East, Guangzhou 510060, China; Tel and Fax: +86-20-87343765; E-mail: wangyu@sysucc.org.cn and Zi-Xian Wang, Department of Medical Oncology, Sun Yat-Sen University Cancer Center, 651 Dong Fend Road East, Guangzhou 510060, China; Tel and Fax: +86-20-87343795; E-mail: wangzx@sysucc.org.cn

(c) Ivyspring International Publisher. This is an open access article distributed under the terms of the Creative Commons Attribution (CC BY-NC) license (https://creativecommons.org/licenses/by-nc/4.0/). See http://ivyspring.com/terms for full terms and conditions.

Received: 2018.09.18; Accepted: 2019.04.29; Published: 2019.06.02

\begin{abstract}
Objective: The purpose of this prospective study was to investigate the perceptions and attitudes to participate in radical and palliative clinical trials among Chinese lymphoma and head/neck cancer patients.

Patients and Methods: A self-developed questionnaire was administered to hospitalized patients in the Department of Medical Oncology in Sun Yat-Sen University Cancer Center between 20 September 2014 and 20 September 2015. This study included lymphoma patients who were enrolled into a radical treatment clinical trial, and head/neck cancer patients participating in a palliative clinical trial.

Results: There were 136 lymphoma patients and 87 head/neck cancer patients who completed and returned the questionnaire. The questionnaire return rate was $100 \%$. More than $90 \%$ of the patients in both groups showed trust and acceptance for medical care personnel, and more than $50 \%$ of the patients in both groups were in hope of trying new medication, receiving free medication, and receiving new treatment at an earlier rate. As compared with those in the radical trials, patients in the palliative clinical trials were more likely to hope to try new medication $(P<0.001)$ and receive a new treatment at an earlier date $(P=0.025)$, but less likely to hope to receive free medication $(P=0.047)$.

Conclusions: This study reveals several shared perceptions and needs of patients in both the radical (lymphoma) and palliative (head/neck cancer) settings and explores the differences in patients' attitudes between radical clinical trials and palliative clinical trials. These findings may provide a basis for improving recruitment of patients for different types of clinical trials and ensuring that patients have a better understanding of clinical trials.
\end{abstract}

Key words: radical clinical trials; palliative clinical trials; differences in perception; new treatment; free medication; patient recruiting

\section{Introduction}

Clinical trials refer to any investigation in human subjects intended to discover or verify the clinical, pharmacological and/or other pharmacodynamic effects of one or more investigational medicinal product(s), and/or to identify any adverse reactions to one or more investigational medicinal product(s) 
and/or to study absorption, distribution, metabolism and excretion of one or more investigational medicinal product(s) with the object of ascertaining its (their) safety and/or efficacy.[1] Historical data reveals that $<2 \%$ of all foreign cancer patients participate in clinical trials, ${ }^{[2]}$ and in spite of the fact that more domestic clinical trials have been initiated in recent years, $<1 \%$ of Chinese patients participate in clinical trials. ${ }^{[3]}$ Accordingly, to further promote the development of clinical trials, and maximize the benefit in terms of determining the efficacy and safety of experimental drugs, it will be necessary to gain a better understanding of factors influencing the participation of patients in trials. A growing number of clinical trials involving anti-cancer drugs are being conducted, and clinical trials are becoming increasingly commonplace in China. Nevertheless, there have been no systematic domestic studies to elucidate factors influencing the perceptions and attitudes of patients participating in radical and palliative clinical trials, and the differences in such factors. In light of the background of clinical trials in China, we designed a targeted questionnaire to investigate the perceptions and attitudes of domestic patients with lymphoma or head/neck cancer participating in radical and palliative clinical trials, respectively, that the aim of this study is to provide reference data that can be used to improve the implementation of various types of clinical trials.

\section{Patients and Methods}

One hundred thirty-six patients with confirmed diagnoses of lymphoma and 87 patients with head/neck cancer undergoing treatment in Sun Yat-Sen University Cancer Center between 20 September 2014 and 20 September 2015 were enrolled in the current study. The pathologic and immunohistochemical results of all patients were reviewed in consultation with Department of Pathology of Sun Yat-Sen University Cancer Center.

The lymphoma group was designated group 1 (the radical clinical trial group) with the following inclusion criteria: 1 . pathologically-confirmed lymphoma; 2. participation in a clinical trial for the radical treatment of lymphoma in Sun Yat-Sen University Cancer Center; 3 . willingness to complete a clinical trial intention survey form; 4 . age $\geq 18$ years and independent awareness and behavior ability; and 5. treatment with at least one course of chemotherapy using a clinical trial drug.

The head/neck cancer group was designated group 2 (the palliative clinical trial group), and had the following inclusion criteria: 1 . pathologicallyproven squamous cell carcinoma of the head/neck; 2 . participation in a clinical trial of palliative treatment of relapsed refractory squamous cell carcinoma of the head/neck in Sun Yat-Sen University Cancer Center; 3.willingness to complete a clinical trial intention survey form; 4 . age $\geq 18$ years and independent awareness and behavior ability; and 5 . treatment with at least one course of chemotherapy using a clinical trial drug.

Clinical trial nurses distributed and collected the survey form to the members of the drug trial groups on a unified basis. The anonymous questionnaire survey method was used in this survey, and a total of 223 questionnaires were distributed. This study was recorded and approved by the Ethics Committee of Sun Yat-Sen University Cancer Center.

Following a review of the literature and consultation with experts, the survey questionnaire was designed for this study. The questionnaire consisted of two major parts. One is the clinical and social characteristics of patients in both groups. The characteristics of patients included age, gender, ECOG performance score, family and educational status, religion, annual income, insurance, and source of medical insurance, whether the treatment was curative, whether or not the patient received free medication. And the other part included the content of the perceptions and attitudes to participate in clinical trial of the patients in both groups (see Supplementary table).

SPSS19.0 statistical software was used for statistical analysis. Data obtained from this study was subjected to descriptive statistical analysis, yielding the age groups of patients participating in the radical and palliative clinical trials, gender ratios, ECOG score characteristics, and the perceptions and attitudes toward the trials. A chi-squared test was used to compare the clinical and subjective factors of the patients participating in the radical and palliative clinical trials, and factors that may have influenced the patients' participation in the trials were subjected to univariate analysis. Multivariate logistic regression analysis was used to assess and identify independent factors influencing patients' perceptions and attitudes toward clinical trials they participated. A $P$ value < 0.05 was defined as a statistically significant difference.

\section{Results}

A total of 223 patients completed the survey, and the questionnaire return rate was $100 \%$. The subjects included 136 patients with confirmed lymphomas who participated in lymphoma clinical trials aimed to be radical, and 87 patients with confirmed cancers of the head/neck who participated in a clinical trial for palliative treatment. The clinical and social characteristics of patients in both groups, and the 
characteristics of the trials in which they participated are shown in Table 1.

Table 1. Clinical and demographic characteristics of lymphoma and head/neck cancer patients and clinical trial characteristics

\begin{tabular}{|c|c|c|c|}
\hline Characteristics & $\begin{array}{l}\text { The radical clinical } \\
\text { trial, } \mathrm{n}(\%)\end{array}$ & $\begin{array}{l}\text { The palliative } \\
\text { clinical Trial, } \mathrm{n}(\%)\end{array}$ & $\begin{array}{l}P \\
\text { value }\end{array}$ \\
\hline \multicolumn{4}{|l|}{ Age, years } \\
\hline$<60$ years & $103(75.7)$ & $72(82.8)$ & \\
\hline$\geq 60$ years & $33(24.3)$ & $15(17.2)$ & 0.213 \\
\hline \multicolumn{4}{|l|}{ Gender } \\
\hline Male & $95(69.9)$ & $70(80.5)$ & \\
\hline Female & $41(30.1)$ & 17 (19.5) & 0.078 \\
\hline \multicolumn{4}{|l|}{ ECOG score } \\
\hline $0-1$ & $134(98.5)$ & 77 (88.5) & \\
\hline $2-3$ & $2(1.5)$ & $10(11.5)$ & 0.001 \\
\hline \multicolumn{4}{|l|}{ Treatment phase } \\
\hline Initial treatment & $71(52.2)$ & $23(26.4)$ & \\
\hline Retreatment & $65(47.8)$ & $64(73.6)$ & 0.001 \\
\hline \multicolumn{4}{|l|}{ Marital status } \\
\hline Unmarried & $12(8.8)$ & $4(4.6)$ & \\
\hline Married & $124(91.2)$ & $83(95.4)$ & 0.139 \\
\hline \multicolumn{4}{|l|}{ Have children } \\
\hline Yes & $120(88.2)$ & $83(95.4)$ & \\
\hline No & $16(11.8)$ & $4(4.6)$ & 0.068 \\
\hline \multicolumn{4}{|l|}{ Living environment } \\
\hline Rural & $40(29.4)$ & 19 (21.8) & \\
\hline Town & $34(25.0)$ & $28(32.2)$ & \\
\hline City & $62(45.6)$ & $40(46.0)$ & 0.344 \\
\hline \multicolumn{4}{|l|}{ Family address } \\
\hline Outside province & $52(38.2)$ & $27(31.0)$ & \\
\hline In province & $84(61.8)$ & $60(69.0)$ & 0.273 \\
\hline \multicolumn{4}{|l|}{ Education } \\
\hline Elementary school and below & $23(16.9)$ & $18(20.7)$ & \\
\hline $\begin{array}{l}\text { Junior high school, high } \\
\text { school, special secondary } \\
\text { school }\end{array}$ & $66(48.5)$ & $50(57.5)$ & \\
\hline $\begin{array}{l}\text { Junior college, university, and } \\
\text { above }\end{array}$ & $47(34.6)$ & $19(21.8)$ & 0.127 \\
\hline \multicolumn{4}{|l|}{ Religion } \\
\hline Yes & $20(14.7)$ & $7(8.0)$ & \\
\hline No & $116(85.3)$ & $80(92.0)$ & 0.137 \\
\hline \multicolumn{4}{|l|}{$\begin{array}{l}\text { Annual income/economic } \\
\text { status }\end{array}$} \\
\hline$\leq 50,000$ & $104(76.5)$ & $56(64.4)$ & \\
\hline$>50,000$ & $32(23.5)$ & $31(35.6)$ & 0.050 \\
\hline \multicolumn{4}{|l|}{ Health insurance } \\
\hline Yes & $59(43.4)$ & $36(41.4)$ & \\
\hline No & $77(56.6)$ & $51(58.6)$ & 0.783 \\
\hline \multicolumn{4}{|l|}{$\begin{array}{l}\text { Whether or not there was free } \\
\text { medicine }\end{array}$} \\
\hline Yes & $110(80.9)$ & $87(100.0)$ & \\
\hline No & $26(19.1)$ & $0(0.0)$ & 0.001 \\
\hline \multicolumn{4}{|l|}{ Clinical trial stage } \\
\hline Stage 1-2 & $14(10.3)$ & $9(10.3)$ & \\
\hline Stage 3-4 & $122(89.7)$ & $78(89.7)$ & 0.990 \\
\hline
\end{tabular}

Most of the clinical and socioeconomic characteristics were balanced between patients in the radical and palliative groups. However, a higher percentage of patients in the palliative group had a poorer performance status than in the radical clinical trials $(11.5 \%$ vs. $1.5 \%, P=0.001)$, and patients in the radical group had a higher percentage of receiving initial treatment than those in the palliative group (52.2\% vs. $26.4 \%, P=0.001$ ).

The differences between perceptions and attitudes toward clinical trials among patients between groups are shown in Table 2. More than 90\% of the patients in both groups showed trust and acceptance for medical care personnel, hoped to benefit themselves, or chose to participate in trials per specialists' recommendation, and more than $50 \%$ of the patients in both groups were in hope of trying new medication in advance, receiving free medication, contributing themselves to medical research, receiving better medical care, and receiving new treatment at an earlier rate. As compared with those in the radical group, patients in the palliative group were more likely to hope to try new medication ( $87.4 \%$ vs. $66.2 \%, P<0.001)$, to hope that participation in the trial would benefit others $(81.6 \%$ vs.67.6\%, $P=0.022)$, to be dissatisfied with their current treatment $(28.7 \%$ vs. $14.7 \%, P=0.011)$, to believe that there was no other effective treatment method $(46.0 \%$ vs.33.1\%, $P=0.002)$, and to hope that participation in the trial would enable them to receive a new treatment at an earlier date $(88.5 \%$ vs. $76.5 \%, P=0.025)$, but less likely to hope to receive free medication (50.6\% vs. $64.0 \%, P=0.047$ ).

The results of multivariate logistic analyses demonstrated independent factors influencing patients' perceptions and attitudes towards clinical trials (Table 3). As compared with those in the radical group, patients in the palliative group more commonly hoped to try new medication (HR, 3.32; $P=0.002)$, benefit others (HR, 2.79; $P=0.004)$, and receive new treatment at an earlier date $(\mathrm{HR}, 2.37$; $P=0.028)$, and believed that there was no other effective treatment (HR, 2.07; $P=0.012$ ).

As shown in Table 3, having kids and living in town were associated with patients' hope to try new medicine; patients aged over 60 were more likely to hold hope to benefit others and less likely to feel dissatisfied with current treatment than younger ones; patients with higher income and those with religion had a higher tendency towards dissatisfaction with their current treatment; town and city residents as well as patients with higher incomes less commonly hoped for free medication; and patients receiving initial treatment were more likely to hope to benefit others and less likely to believe that there was no other effective treatment.

\section{Discussion}

The present prospective study investigated several aspects of perceptions and attitudes among lymphoma patients in radical clinical trials and head/neck cancer patients in palliative clinical trials. We found that the majority of patients in both groups were in hope of trying new medication and receiving free medication. As compared with those in the palliative group, a higher percentage of patients in the radical clinical trial group entered the clinical trial 
hoping to receive free medication, which suggests that patients in radical clinical trials might be more concerned about economic factors than those in palliative trials.

Table 2. Differences in perceptions and attitudes toward clinical trials of lymphoma and head/neck cancer patients

\begin{tabular}{|c|c|c|c|c|c|c|}
\hline Characteristics & $\begin{array}{l}\text { The radical } \\
\text { clinical trial, } \mathbf{n} \\
(\%)\end{array}$ & $\begin{array}{l}\text { The palliative } \\
\text { clinical trial, } n \\
(\%)\end{array}$ & $\begin{array}{l}P \\
\text { value }\end{array}$ & $\begin{array}{l}\text { Table 3. Multivariate regre } \\
\text { perceptions and attitudes to }\end{array}$ & $\begin{array}{l}\text { sion analysis o } \\
\text { articipate in cli }\end{array}$ & $\begin{array}{l}\text { ctors influencing } \\
\text { I trials.* }\end{array}$ \\
\hline Hoped to try new medication & & & & & & \\
\hline Yes & $90(66.2)$ & $76(87.4)$ & & Factors & HR $(95 \%$ CI) & $P$ value \\
\hline No & $46(33.8)$ & $11(12.6)$ & $<0.001$ & Hope to try new medication & & \\
\hline Hoped to receive free medication & & & & Goal of the clinical trial & & 0.002 \\
\hline Yes & $87(64.0)$ & $44(50.6)$ & & Radical & 1 & \\
\hline No & $49(36.0)$ & $43(49.4)$ & 0.047 & Palliative & $3.32(1.54,6.84)$ & \\
\hline Trust in the hospital & & & & Have children & & 0.045 \\
\hline Yes & $133(97.8)$ & $87(100.0)$ & & Yes & 1 & \\
\hline No & $3(2.2)$ & $0(0.0)$ & 0.163 & No & $0.36(0.13,0.98)$ & \\
\hline Trust in the physician & & & & Living environment & & 0.01 \\
\hline Yes & $134(98.5)$ & $86(98.9)$ & & Rural & 1 & \\
\hline No & $2(1.5)$ & $1(1.1)$ & 0.839 & Town & $3.82(1.36,10.72)$ & \\
\hline Others' recommendation & & & & City & $0.88(0.42,1.81)$ & \\
\hline Yes & $44(32.4)$ & $23(26.4)$ & & Hoped to receive free medication & & \\
\hline No & $92(67.6)$ & $64(73.6)$ & 0.347 & Living environment & & 0.001 \\
\hline Specialist's recommendation & & & & Rural & 1 & \\
\hline Yes & $127(93.4)$ & $86(98.85)$ & & Town & $0.69(0.30,1.58)$ & \\
\hline No & $9(6.62)$ & $1(1.15)$ & 0.054 & City & $0.27(0.13,0.57)$ & \\
\hline $\begin{array}{l}\text { Hoped to make a contribution to } \\
\text { medical research }\end{array}$ & & & & $\begin{array}{l}\text { Annual income/economic status } \\
\leq 50,000\end{array}$ & 1 & 0.002 \\
\hline Yes & $84(61.8)$ & $60(69.0)$ & & $>50,000$ & $0.37(0.19 .0 .70)$ & \\
\hline No & $52(38.2)$ & $27(31.0)$ & 0.273 & $\begin{array}{l}\text { Dissatisfaction with current } \\
\text { treatment }\end{array}$ & & \\
\hline Hoped to benefit others & & & & Age & & 0.038 \\
\hline Yes & $92(67.6)$ & $71(81.6)$ & & $\begin{array}{l}\text { Age } \\
<60 \text { years }\end{array}$ & 1 & \\
\hline No & $44(32.4)$ & $16(18.4)$ & 0.022 & $\geq 60$ years & $0.31(0.10,0.94)$ & \\
\hline $\begin{array}{l}\text { Hoped to benefit oneself } \\
\text { Yes }\end{array}$ & & & & Religion & & 0.035 \\
\hline $\begin{array}{l}\text { Yes } \\
\text { No }\end{array}$ & $\begin{array}{l}133(97.8) \\
3(2.2)\end{array}$ & $\begin{array}{l}86(98.9) \\
1(1.1)\end{array}$ & 0.562 & Yes & 1 & \\
\hline Dissatisfaction with current treatment & & $1(1.1)$ & & No & $8.97(1.17,68.67)$ & \\
\hline Yes & $20(14.7)$ & $25(28.7)$ & & Annual income/economic status & & 0.044 \\
\hline No & $116(85.3)$ & $62(71.3)$ & 0.011 & $\leq 50,000$ & 1 & \\
\hline $\begin{array}{l}\text { Wished to obtain better care and } \\
\text { monitoring }\end{array}$ & $110(00.0)$ & $02(1.0)$ & 0.011 & $\begin{array}{l}>50,000 \\
\text { Hope to benefit others }\end{array}$ & $2.08(1.02,4.22)$ & \\
\hline Yes & $95(69.9)$ & $71(81.6)$ & & Goal of the clinical trial & & 0.004 \\
\hline No & $41(30.1)$ & $16(18.4)$ & 0.050 & Radical & 1 & \\
\hline $\begin{array}{l}\text { Afraid of receiving discriminatory } \\
\text { treatment }\end{array}$ & & & & $\begin{array}{l}\text { Palliative } \\
\text { Age }\end{array}$ & $2.79(1.39,5.59)$ & 0.032 \\
\hline Yes & $44(32.4)$ & $22(25.3)$ & & $<60$ years & 1 & \\
\hline No & $92(67.6)$ & $65(74.7)$ & 0.260 & $\geq 60$ years & $2.54(1.08,5.96)$ & \\
\hline Belief that there was no other effective & & & & Treatment phase & & 0.032 \\
\hline treatment method & & & & Initial treatment & 1 & \\
\hline Yes & $45(33.1)$ & $40(46.0)$ & & Retreatment & $0.49(0.25,0.94)$ & \\
\hline No & $91(66.9)$ & $47(54.0)$ & 0.002 & Belief that there was no other & & \\
\hline Hope the clinical trial had good results & & & & effective treatment method & & \\
\hline Yes & $104(76.5)$ & $71(81.6)$ & & Goal of the clinical trial & & 0.012 \\
\hline No & $32(23.5)$ & $16(18.4)$ & 0.362 & Radical & 1 & \\
\hline $\begin{array}{l}\text { Hope to receive new treatment at an } \\
\text { earlier date }\end{array}$ & & & & Palliative & $2.07(1.17,3.67)$ & \\
\hline $\begin{array}{l}\text { earlier date } \\
\text { Yes }\end{array}$ & & & & Treatment phase & & 0.044 \\
\hline Yes & $104(76.5)$ & $77(88.5)$ & & Initial treatment & 1 & \\
\hline No & $32(23.5)$ & $10(11.5)$ & 0.025 & Retreatment & $1.81(1.02,3.22)$ & \\
\hline $\begin{array}{l}\text { Worried that refusal to participate } \\
\text { would jeopardize relationship with } \\
\text { one's physician }\end{array}$ & & & & $\begin{array}{l}\text { Hope to receive new treatment at an } \\
\text { earlier date }\end{array}$ & & \\
\hline $\begin{array}{l}\text { Yes } \\
\text { Yesician }\end{array}$ & $16(11.8)$ & $15(17.2)$ & & Goal of the clinical trial & 1 & 0.028 \\
\hline No & $120(88.2)$ & $72(82.8)$ & 0.249 & $\begin{array}{l}\text { Kadical } \\
\text { Palliative }\end{array}$ & $2.37(1.10,5.11)$ & \\
\hline $\begin{array}{l}\text { Participated due to factors connected } \\
\text { with the treatment environment }\end{array}$ & & & & * Only significant factors retained in $\mathrm{t}$ & e final logistic mod & re shown in the table. \\
\hline Yes & $33(24.3)$ & $24(27.6)$ & & & & \\
\hline No & $103(75.7)$ & $63(72.4)$ & 0.579 & However, this ob & erved assoc & ion might be \\
\hline $\begin{array}{l}\text { Participated due to the drug's } \\
\text { administration pathway in the clinical } \\
\text { trial }\end{array}$ & & & & $\begin{array}{l}\text { explained by the higher } \\
\text { radical clinical trial gro }\end{array}$ & $\begin{array}{l}\text { percentage } \\
\text { up with low }\end{array}$ & $\begin{array}{l}\text { batients in the } \\
\text { comes as this }\end{array}$ \\
\hline Yes & $57(41.9)$ & $33(37.9)$ & & association became ir & significant & multivariate \\
\hline
\end{tabular}

\begin{tabular}{llll}
\hline Characteristics & $\begin{array}{l}\text { The radical } \\
\text { clinical trial, } \mathbf{n} \\
\mathbf{( \% )}\end{array}$ & $\begin{array}{l}\text { The palliative } \\
\text { clinical trial, } \mathbf{n} \\
\mathbf{( \% )}\end{array}$ & $\begin{array}{l}\boldsymbol{P} \\
\text { value }\end{array}$ \\
\hline $\begin{array}{l}\text { No } \\
\text { Self-assessment of understanding of } \\
\text { clinical trial }\end{array}$ & $79(58.1)$ & $54(62.1)$ & $\mathbf{0 . 5 5 5}$ \\
$\begin{array}{l}\text { Poor } \\
\text { Average }\end{array}$ & $68(50.0)$ & $35(40.2)$ & \\
Extensive & $61(44.9)$ & $50(57.5)$ & \\
\hline
\end{tabular}
.

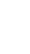


analysis. In contrast, multivariate analysis demonstrated that access to a new drug or new treatment was more attractive to patients participating in palliative trials than those in radical trials. One possible explanation is that most $(>70 \%)$ of the patients in the palliative group had failed initial treatment and urged for a new drug offering improved effectiveness and lengthened survival.

Of note, multivariate analyses also revealed several other factors influencing patients' attitudes to participate in clinical trials, regardless of the radical or palliative setting. These factors also need attention and could cast light on how to conduct these trials more humanely and better accepted. For instance, patients with kids more commonly hoped for a new drug than those without kids, which implied support and advice from offspring was very important and could be of great assistance in convincing patients who held wrongly negative opinions of new drugs.

This study also found that the vast majority $(>90 \%)$ of the patients in both the radical and palliative groups participated in a clinical trial due to trust in the hospital and their specialists, and negative attitudes such as dissatisfaction with current treatment were not common motives for participating in clinical trials. Trust should be considered as a crucial factor in decision making concerning clinical trial participation. A review of international research results suggests that there are differences in Chinese patients' and international patients' trust when deciding whether or not to participate in clinical trials. Specifically, international patients' willingness to enter a clinical trial is chiefly influenced by their family physicians ${ }^{[4-6]}$, but past research suggests that Asian patients' willingness to participate in a clinical trial is chiefly influenced by the views of friends and relatives ${ }^{[7-9]}$. In this study, however, patients' decisions were most strongly influenced by specialist physicians in both the radical and palliative groups. This finding may reflect differences in domestic and international medical systems where patients tend to rely more on the doctor who are close to them and earn their trust through the clinical practice process in the first place. This attitude is reflected in the increasingly positive perception of clinical trials among patients in China during recent years.

Economic compensation remains controversial in practice. International research has shown that economic compensation may constitute a hindrance to the implementation of clinical trials because while experimental drugs tend to be costly and difficult to obtain, economic compensation provided by research organizations often causes subjects to engage in wild speculation. ${ }^{[10]}$ In contrast, other studies have shown that economic compensation, such as meal subsidies or free parking, will encourage patients to participate in trials [11-15]. The current study showed that patients in both radical and palliative groups hoped to receive free medication, and that patients with a lower income were more likely to hope to receive free medication. These findings suggest that economic compensation might exert a positive influence on some Chinese patients' decisions regarding participation in a clinical trial, particularly considering the characteristics of the medical system of China. Because our hospital is a first-rate 3A oncology hospital, most of the patients seeking care at this hospital have relatively few mental reservations about participation in a clinical trial. Furthermore, there are differences in health insurance systems in China and abroad. Not everyone is covered by the health insurance system in China, and some rural medical insurance policies have low reimbursement rates. Patients receiving medical treatment in China may consequently have a greater economic burden than their international counterparts, and domestic patients participating in clinical trials will have a greater demand for free medication or economic compensation.

Chinese clinical trials are still at an early stage with respect to scale and development, and there have been few attempts to assess the perceptions of Chinese patients participating in trials, and most of these studies have focused on differences in perceptions among patients consenting or refusing to participate in trials. ${ }^{[16]}$ This was the first study to compare the different perceptions and needs of Chinese patients participating in different types of clinical trials (radical vs. palliative), and also broke ground with its large-scale comparison of the perceptions and attitudes of Chinese patients participating in different clinical trials.

Apart from the factors discussed above, previous studies found that propaganda and education addressing trial information could influence the patients' attitudes and perceptions toward clinical trials as well. The variation in knowledge of clinical trials held by primary care physicians and nurse practitioners could result in different efficiency in patient accrual and hence different probability of recruitment of participants. ${ }^{[17-18]}$ Our institution is a high-volume cancer center and the doctors and nurses in our institution are well-known of clinical trials and can adequately inform participants of well-organized education about the trial they signed in, which guarantees a high proportion of patients recruited in clinical trials from our institution. Moreover, brief multimedia psychoeducational intervention was also proved to be a better tool for improving patients' perceptions compared to traditional printed 
educational information. [19]

This study has several limitations. First of all, Kaplan et al. [20] concluded that patients with a proactive, optimistic attitude will account for a relatively large share of clinical trial participants; however, because the content of the questionnaire in this study did not investigate the effect of patient mental status on participation in clinical trials, this subject needs further research. Second, only limited cancer types for radical and palliative clinical trials were enrolled in this study, which might have confined extension of the conclusion to other tumors. Third, there was no quality-control question set in the questionnaire, which however did not impair the powerfulness of the analysis results.

In conclusion, this study reveals several shared perceptions and needs of patients in both the radical (lymphoma) and palliative (head/neck cancer) groups and explores the differences in patients' attitudes between radical clinical trials and palliative clinical trials. We should establish different points of emphasis when communicating with patients considering participating in different types of clinical trials. We hope the trends and tendencies discovered by this study could also provide a better basis for recruiting specific patients for different types of clinical trials and instilling correct perceptions of clinical trials among Chinese patients.

\section{Acknowledgements}

We thank the staff of Department of Medical Oncology and Department of Clinical Research, Sun Yat-Sen University Cancer Center for their constructive suggestions. And we thank all the patients who participated in this study.

\section{Competing Interests}

The authors have declared that no competing interest exists.

\section{References}

[1] Aronson JK. What is a clinical trial? Br J Clin Pharmacol. 2004;58(1):1-3.

[2] Murthy VH, Krumholz HM, Gross CP. Participation in cancer clinical trials: race, sex, and age based disparities. JAMA. 2004;291(22):2720-2726..

[3] Zhang QH, Zhang S, Jia YT, et al. Analysis and evaluation of influencing factors for patients' participation in drug clinical trials. Chinese General Practice, 2016, 19 (3) :368 - 372.

[4] Madsen SM, Holm S, Davidsen B, et al. Ethical aspects of clinical trials: the attitude of participants in two non-cancer trials. J Intern Med, 2000, 248 (6): 463-474.

[5] Mancini J, Genève J, Dalenc F, et al. Decision-making and breast Cancer clinical trials-How experience challenges attitudes. Contemp Clin Trials, 2007, 28 (6): 684-694.

[6] Udrea G, Dumitrescu B, Purcarea M, et al. Patients' perspectives and Motivators to participate in clinical trials with novel therapies for rheumatoid arthritis. J Med Life, 2009, 2 (2): 227-231.

[7] Brown RF, Cadet DL, Houlihan RH, et al. Perceptions of participation in a phaseI, II or III clinical trials among African American patients with cancer: what do refusers say? J Oncol Pract, 2013, 9 (6): 287 - 293.

[8] Wu E, Wang T, Lin T, et al. A comparative study of patients' Attitudes toward clinical research in the United States and urbanand Rural China. Clin Transl Sci, 2015, 8 (2): 123- 131.
[9] Hussain - Gambles M. South Asian patients' views and experiences of clinical trials participation. Fam Pract, 2004, 21 (6): 636- 642.

[10] Shaw MG, Morrell DS, Corbie-Smith GM, et al. Perceptions of pediatric clinical research among African American and Caucasian parents. J Natl Med Assoc, 2009, 101 (9): 900-907.

[11] Cao Ye, Gao Wen Chao, Zheng Shangyou, et al. Attitudes of Patients to New Drug clinical trials of Cancer Therapy. China Cancer, 2011, 20 (9): 659- 664.

[12] Guedj M, Ballester S, Kamar N, et al. Patients' motives for consenting or refusing to participate in a clinical trial in organ transplantation. Clin Transplant, 2013, 27(5): 724- 731.

[13] Nabulsi M, Khalil Y, Makhoul J. Parental attitudes towards and perceptions of their children' s participation in clinical research: a developing - country perspective. J Med Ethics, 2011, 37 (7): 420 - 423.

[14] Sengupta S, Strauss RP, DeVellis R, et al. Factors affecting African-American participation in AIDS research. J Acquir Immune Defic Syndr, 2000, 24 (3): 275 -284 .

[15] Sood A, Prasad K, Chhatwani L, et al. Patients' attitudes and preferences about participation and recruitment strategies in clinical trials. Mayo Clin Proc, 2009, 84 (3): 243 - 247.

[16] Kong Q, Mei H, Lai Y, et al. Barriers and facilitators to participation in clinical trial among lymphoma patients from Sun Yat-sen University Cancer Center in China: An observation study. Medicine (Baltimore) 2017; 96(37):e8062.

[17] Ulrich, C.M., Zhou Q., Ratcliffe S.J., et al. Nurse Practitioners' attitudes about cancer clinical trials and willingness to recommend research participation. Contemp Clin Trials, 2012; 33(1): 76-84

[18] Bylund, C.L., Weiss E.S., Michaels M., et al. Primary care physicians' attitudes and beliefs about cancer clinical trials. Clin Trials. 2017; 14(5): 518-525.

[19] Jacobsen, P.B., Wells K.J., Meade C.D., et al. Effects of a brief multimedia psychoeducational intervention on the attitudes and interest of patients with cancer regarding clinical trial participation: a multicenter randomized controlled trial. J Clin Oncol, 2012; 30(20): 2516-21.

[20] Kaplan CP, Nápoles AM, Narine S, et al. Knowledge and attitudes regarding clinical trials and willingness to Participate among prostate cancer patients. Contemporary Clinical trials 2015,45(Pt B): 443-448. 